\title{
New research network for studies in the curatorial
}

\author{
Anne Folke Henningsen \& Malene Vest Hansen
}

The Danish Research Council has provided funding for a new international network, Research network for curatorial studies, (ca. 1 million dkr.) for a two-year period. The network is based at University of Copenhagen with principal leaders Malene Vest Hansen, Ph.D. in Art History, Department of Arts and Cultural Studies, and Anne Folke Henningsen, Ph.D. in History, the Saxo Institute. The following is a short introduction to the background for and the objectives of the network.

Curatorial Studies is an academic field exploring the cultural functions of curating and its relation to knowledge production in exhibitions, museums, and display culture. The aim of the network is to enhance research in curatorial studies by bringing together scholars from an interdisciplinary field, based in both universities and in museums. The interdisciplinary scope of the network will combine knowledge from practice based and academic research and cross-fertilize research into vital aspects of the changing roles of curating in contemporary society. The network will thus strengthen the Danish research field with potential international impact. The network favors collaboration with teams in Nordic research institutions in order to consolidate curatorial studies in the area and prepare for future collaborative research and educational projects.

\section{THE OBJeCtives ARE TO}

- strengthen international collaboration and research in critical curatorial studies

- initiate and strengthen research collaboration in the curatorial between scholars in both universities and in museums

- organize knowledge exchange activities, conferences, explorative workshops and seminars on the change in the curatorial in contemporary society

- publish findings in both print and web observing open access principles

- prompt future research projects and education initiatives in curatorial studies potentially across institutional and disciplinary boundaries

\section{Key RESEARCH QUESTIONS IN STUdIES IN THE CURATORIAL}

Curatorial Studies is an emerging international academic field, forming a particular line within the broader field of museum studies. Critical curatorial studies explore the cultural functions of curating and its relation to knowledge production, exhibitions, museums and other institutions, audiences, art and display culture. Previously, a curator was defined as engaged in traditional museum practice (acquiring, conserving, researching, communicating) 
124 and exhibition making. Today, however, the exhibition aspect is emphasized and the curatorial presents an expanded field of strategies where theory and practice entangle and encompass vital social and cultural conditions. In the art world, the term "curator" is now increasingly in use for an "exhibition-maker" - (in Danish this new role of curator is defined "kurator" and distinguished from the traditional curator, "museumsinspektør") - and new educations in curating emerge.

While the spatialized discourse of objects remains vital, curating also partakes in expanded cultural practices. The curatorial engages in producing exhibitions for audiences to view as well as in changing aesthetic experience, in framing cultural conditions in museums and social space, and in investigating constructions of knowledge and ideology.

In critical museum studies the museum is defined as "one of the most central and indispensable framing institutions of modernity" (Preziosi 2004:71); the museum's collections of cultural heritage create narratives shaping dominant ideas and perceptions of time, space, history, subject formation and nation formation. In the past decades, however, the role of museums has changed and so has the importance of exhibitions. The exhibition is today the primary site of cultural exchange; part spectacle, part socio-historical event, and part structuring device, exhibitions establish and administer meanings of art and cultural heritage (Greenberg et al. 1996).

As exhibitions gain in importance, so do curatorial strategies, why new research and definitions are called for: What constitutes the curatorial? What sort of knowledge is produced in curatorial strategies? How can we rethink the role of the curator in regard to material objects, to art practices, audiences, platforms, sites and institutions? How do exhibitions engage their users? How do curatorial strategies inform museums in contemporary society and what sort of conservative, or maybe critical and transformative, potentials can be traced in exhibition cultures? The research network will primarily investigate these questions in relation to three major themes:

1. Interventions: contemporary artists in cultural history museums (and vice-versa)

2. Participatory practices and strategies

3. Museum edification: challenges of curating in contemporary society

In order to support cross-fertilization in critical thinking, each subtheme will be focused on in interdisciplinary set-ups in seminars, exploratory workshops and conferences for members of the network to meet in discussions face-to-face. The network seeks to enhance the research field and set the ground for future research projects within curatorial studies, thus it is designed carefully to include both distinguished researchers as well as young doctorates.

\section{STATE OF THE ART}

With the specific focus on the curatorial the network aims at securing a platform for new research in the emerging field and developing a new phase within the field of critical museum studies. Two decades ago, the so called "new museology" gave rise to important research initiatives, also in Denmark, with networks and publications such as Dansk museologisk netværk, the journal Nordisk Museologi, and Ingemann and Hejlskov Larsen's $N y$ dansk museologi, 2005.

Dansk Center for Museumsforskning, (Danish Center for Museum Research, museumsforskning.dk), founded in 2011, marks a 
milestone in connecting representatives from departments in Danish universities engaged in museum studies, thus mapping a very broad field. In Denmark at present, actual research in museum studies is scattered as documented by the Danish Center for Museum Research (report by Villadsen \& Drotner, 2012).

The Research Network for Studies in the Curatorial will thus mark a point of departure from the state of the art of the research field in Denmark in two important aspects: 1) the specific focus on the curatorial (exhibition aspects) to be investigated in collaboration by 2) researchers and curators from both universities and museums.

The network will support a growing research interest in the curatorial, also discernable in the increasing number of doctorate students engaged in projects related to the key questions of the curatorial research network. It will give priority to interdisciplinary collaboration and transinstitutional research collaboration in order to found possible future research and education, including doctoral studies.

The network favors collaboration with teams in Nordic research institutions in order to consolidate curatorial studies in the area and prepare for future collaborative research. The Research Network for Studies in the Curatorial will thus strengthen the Danish research field with potential international impact.

\section{Milestones}

Milestones in the designated two-year period (October 2014 - September 2016) will be:

Kick-off conference at the University of Copenhagen, early 2015: A conference with keynote speakers invited to address the three major research themes to be investigated in the research network and frame the future research collaboration. Number of participants: 50 . The kick off conference will welcome all members of the network.

Three seminars/explorative workshops will be organized in 2015 in different locations, each addressing one of the three key themes. Number of participants for each explorative workshop: approximately 15 .

Concluding conference with open call, Copenhagen spring 2016: A two-day international conference Curatorial Challenges will include invited keynote speakers from the network as well as papers selected from an open call. This conference will be open for a wider public. Number of participants expected: 100 .

Masterclasses/Ph.D. seminars: In relation to the seminars and the concluding conference master classes and Ph.D.-seminars will be organized at the hosting university/museum.

\section{NETWORK DESIGN}

The Research Network for Studies in the Curatorial will gather a diverse and gender balanced group of approximately 50 researchers and consist of established and prominent professors, mid-career academics as well as young academics from an interdisciplinary academic field. The researchers are primarily based in museum studies, art history, ethnology, cultural studies, anthropology, and history at international universities and also curators in museums and other cultural exhibition and research institutions.

In order to both secure the international scope of the curatorial research project and to prepare future consolidation of the research field in Denmark and the Nordic countries the network members are selected among international, though primarily Nordic, researchers and curators. 


\section{LITERATURE}

Greenberg, Rosa, Bruce W. Ferguson \& Sandy Nairn (eds.) 1996. Thinking about Exhibitions. London: Routledge.

Ingemann, Bruno \& Ane Hejlskov Larsen 2005. Ny dansk museologi. Århus: Aarhus Universitetsforlag.

Preziosi, Donald 2004. "Brain of the earth's body: Museums and the framing of modernity." In Bettina Messias Carbonell (ed.). Museum Studies. An Anthology of Contexts. Malden: Blackwell Publishing.

Villadsen, Rikke \& Kirsten Drotner 2012.

"Dansk museumsforskning: status og tendenser." Odense: Danish Centre for Museum Research. www.museumsforskning.dk

Malene Vest Hansen, associate professor in art history, vest@hum.ku.dk

Department of Arts and Cultural Studies University of Copenhagen

Karen Blixensvej 1

DK-2300 København S, Denmark

Anne Folke Henningsen, assistant professor in ethnology

folke@hum.ku.dk

\section{Saxo Institute}

University of Copenhagen

Karen Blixensvej 4

DK-2300 København S, Denmark 